\title{
Ecoturismo: uma ponte para o turismo sustentável
}

\author{
Ecotourism: a bridge to sustainable tourism
}

\author{
Eduardo Spaolonse, Suzana da Silva de Oliveira Martins
}

\section{RESUMO}

Diversas áreas naturais de importância socioambiental no Brasil agregam comunidades locais. Muitas das comunidades residem nessas áreas e delas tiram a sua sobrevivência há muitas gerações, percebendo-as como território fundamental para sua reprodução social, cultural e econômica. O Ecoturismo de base comunitária desponta como uma possibilidade para 0 desenvolvimento sustentável e econômico dessas comunidades. Este artigo foi construído através de pesquisas bibliográficas baseando-se que 0 Ecoturismo se diferenciou, dos demais segmentos do turismo, por se apoiar em princípios que reforçam o compromisso com a conservação ambiental e o benefício comunitário. Hoje as estatísticas demonstram que Ecoturismo cresce mais que a média do turismo convencional no mundo todo e especialmente no Brasil. Entre estas temáticas observou-se à necessidade de considerar a forma de organização social das comunidades locais na construção dos processos participativos. Com isso espera-se contribuir para uma reflexão sobre o Ecoturismo de base comunitária em uma perspectiva em que a participação comunitária torna-se a base para uma efetiva sustentabilidade, portanto, pretende-se que a compreensão integrada dos temas abordados possa facilitar outros processos semelhantes. Ecoturismo é um segmento da atividade turística que utiliza, de forma sustentável, o patrimônio natural e cultural, incentiva sua conservação e busca a formação de uma consciência ambientalista através da interpretação do ambiente, promovendo o bem-estar das populações envolvidas e dos atores sociais. $O$ aproveitamento desse potencial por meio do desenvolvimento de estratégias que fortaleçam o turismo participativo, solidário e sustentável é, sem dúvida, uma grande oportunidade para o país. Neste processo de transição reside o desafio de serem estabelecidas estratégias e consolidadas práticas que estimulem a valorização cultural, a organização comunitária e a conservação ambiental. Práticas que assegurem o acesso ao compartilhamento dos benefícios gerados pela atividade, com estímulo ao empreendedorismo social e à criação de negócios inclusivos. E que, finalmente, estabeleçam-se arranjos sustentáveis de interação social e das populações com o território e o ambiente em que vivem.

PALAVRAS-CHAVE: Ecoturismo; Turismo; Sustentabilidade. 


\begin{abstract}
Several natural areas of environmental importance in Brazil add local communities. Many of the communities living in these areas and take them to survive for generations, seeing them as a key territory for their social reproduction, cultural and economic. Ecotourism community based emerged as a possibility for sustainable and economic development of these communities. This article was constructed through literature searches based on the Ecotourism differed, the other segments of tourism, by relying on principles that reinforce the commitment to environmental conservation and community benefit. Today the statistics show that Ecotourism is growing more than the average conventional tourism worldwide and especially in Brazil. Among these issues there was the need to consider the form of social organization of local communities in the construction of participatory processes. It is expected to contribute to a reflection on the Ecotourism community based on a perspective that community participation becomes the basis for an effective sustainability, therefore, it is intended that the integrated understanding of topics to facilitate similar processes. Ecotourism is a segment of tourism that uses in a sustainable manner, the natural and cultural heritage, encourages its conservation and seeks the formation of environmental awareness through the interpretation of the environment, promoting the well-being of people involved and the social actors. The use of this potential by developing strategies to strengthen participatory, supportive and sustainable tourism is undoubtedly a great opportunity for the country. In this transition lies the challenge of being established strategies and consolidated practices that encourage cultural development, community organizing and environmental conservation. Practices that ensure access to the sharing of benefits generated by the activity, with encouragement of social entrepreneurship and the creation of inclusive business. And finally, set up sustainable arrangements of social interaction and populations with the territory and the environment in which they live.
\end{abstract}

KEYWORDS: Ecotourism; Tourism; Sustainability.

\title{
Introdução
}

No atual contexto da globalização, o turismo surge como atividade que vem demonstrando grande crescimento nas últimas décadas em todo o mundo. No Brasil, esta atividade está em ascensão, graças as nossas riquezas naturais, ampla extensão territorial e rico patrimônio históricocultural, permitindo ainda a prática da maioria das modalidades de turismo ecológico e também de esportes de aventura, caracterizando o chamado turismo ecológico, ambiental ou ecoturismo.

Essas atratividades naturais e culturais fazem com que o nosso país seja uma atração para esta modalidade turística, onde os próprios brasileiros como os visitantes estrangeiros tenham a possibilidade de conhecer tais patrimônios, levando em consideração a preservação do ambiente (PANOSSO NETTO, 2011, p. 36).

Dentro do Turismo, o segmento Ecoturismo se diferencia dos demais apoiando em princípios que reforçam o compromisso com a conservação ambiental e o benefício comunitário. 
O Ecoturismo cresce na medida em que todos começam a se preocupar com o meio ambiente, com as mudanças climáticas e com as possibilidades da vida em maior contato com a natureza e com a participação das comunidades locais, dos atores sociais que podem participar de iniciativas que venham a contribuir para melhoria da qualidade de vida e também para manter as suas tradições, sem impor mudanças (MICT/MMA, 1994).

Os grandes princípios do ecoturismo resumem-se na célebre frase: "Da natureza nada se tira a não ser fotos, nada se deixa a não ser pegadas, nada se leva a não ser recordações". A ideia é justamente alertar a todos que o ecoturismo de base comunitária segue regras básicas vivamente preocupadas com os problemas ambientais, com a biodiversidade e com a natureza, de uma forma geral (MMA, 1999).

Entretanto, tal concepção gera preocupação de não se ter a sustentabilidade tanto cultural, social, natural e econômica do local onde se vai desenvolver a atividade. Pois sem um planejamento adequado, às consequências serão impactos negativos para a comunidade receptora e para o ecossistema local (SALVATI, 2003, p. 33-38).

A atividade do ecoturismo deve levar em consideração um planejamento adequado para o local, que contribuirá para a diminuição dos impactos ambientais causados na fauna e flora. $O$ crescimento do ecoturismo no Estado do Amazonas provoca a necessidade de levar ao conhecimento da população local, cadeias turísticas e do Brasil, a necessidade de se conservar a natureza, onde não apenas aqueles que estão envolvidos no Turismo, como as próprias comunidades participativas que se preocupam com o seu futuro, pois a cada dia muitos se envolvem com a questão e precisam conhecer um pouco mais o que é a atividade (WWF, 2006, p. 20).

Devem ser buscadas interações sustentáveis e ouvir a comunidade que será impactada pelas mudanças do Ecoturismo, a inclusão social deve ser estabelecida com práticas e estratégias bem estudadas e planejadas para que os benefícios venham a ser atrativos para todos os atores sociais envolvidos.

Assim o objetivo, será demonstrar o aproveitamento desse potencial por meio do desenvolvimento de estratégias que fortaleçam o turismo participativo, solidário e sustentável sendo, sem dúvida, uma grande oportunidade para o país.

Este artigo foi construído através de pesquisas bibliográficas baseando-se que o Ecoturismo se diferenciou entre as diferentes formas de se fazer turismo, por se apoiar em princípios que reforçam o compromisso com a conservação ambiental e o benefício comunitário. "Ecoturismo: uma ponte para o turismo sustentável" tem como base teórica necessária propiciar a relação das atividades do turismo, ecoturismo e sustentabilidade para as comunidades participativas. O artigo após iniciar com a Introdução aborda as atividades do ecoturismo que utilizam a alternativa do desenvolvimento sustentável, que além de mostrar as características do trabalho, também coloca a relação deles com o meio ambiente. $E$ nas 
considerações finais estaremos condescendendo com os autores, numa visão simplória de conhecimentos que buscam acima de tudo contribuírem para o debate acadêmico sobre 0 ecoturismo e 0 desenvolvimento sustentável.

\section{Fundamentação teórica}

Neste artigo foram estabelecidas as fundamentações da construção do referencial teórico que conduziram ao alcance do objetivo proposto neste estudo. Inicialmente foram percorridos os caminhos do turismo, essa atividade multicultural, complexo e diversificado, que depende do desempenho de diversas áreas produtivas e setores públicos e privados para satisfazer com eficiência à demanda dos usuários.

A seguir, foram abordadas as visões do ecoturismo, esse segmento da atividade turística que utiliza, de forma sustentável, o patrimônio natural e cultural, incentiva sua conservação e busca a formação de uma consciência ambientalista através da interpretação do ambiente, promovendo o bemestar das populações envolvidas e dos atores sociais.

$\mathrm{Na}$ sequência foi enfocado o papel da sustentabilidade ou "ecodesenvolvimento", uma atividade que tem direta relação com o desenvolvimento sustentável, haja vista que tem interdependência com os setores econômicos, sociais, ambientais e culturais, objetivando a preservação dos recursos naturais e culturais, com vista a garantir a sustentabilidade da comunidade local onde é desenvolvido.

De acordo Lakatos e Marconi (2006, P. 289),

o referencial teórico não é mera repetição do que já foi dito ou escrito sobre certo assunto, mas propicia a observação de um novo enfoque ou abordagem, chegando a conclusões inovadoras.

\section{Revisão teórica}

Buscar a colaboração e o empreendedorismo no turismo de base local participativo, promover a reflexão e discussão em torno de experiências, métodos, formas e trabalhos que interajam para 0 fortalecimento do Ecoturismo e as comunidades locais que serão impactadas, assim como o poder público e as políticas públicas que serão implantadas, o terceiro setor, a iniciativa privada e os acadêmicos.

Ser um segmento que sirva de transformação da realidade local, sem que essa perca sua essência, seu patrimônio material e imaterial, seus saberes e fazeres e, principalmente, sua cultura e o seu caráter social.

O importante dar ouvido a comunidade local nos seus anseios, nos "medos" e nas suas expectativas, para que participem de forma ativa das decisões que irão impactar o seu lugar, intercedendo para que sejam 
minimizadas as transformações que poderão ocorrer não modificar a cultura e as características do lugar é essencial para uma melhor ponte para um turismo sustentável utilizando-se do seu segmento Ecoturismo.

Trata-se de um fenômeno social multicultural, complexo e diversificado, tanto que atualmente o turismo está apontado, não só atrelado, à ideia de atividade de lazer como o senso comum retrata, mas sim a diversidade de atrativos socioeconômicos que traz sua abrangência e permite a inserção de novas formas de analisar o fenômeno e mobilizar pessoas pelos mais variados motivos para os mais diversos destinos turísticos.

\section{Turismo}

Especialistas em relação à área definem que o Turismo constitui-se, nos dias atuais, como um dos mais importantes instrumentos de geração de emprego e renda e rotatividade de fluxo de pessoas em todo o mundo (BENI, 2001, p. 30).

É o tipo de atividade capaz de alavancar a economia seja ela de um determinado lugar ou pais, além de contribuir significativamente para a preservação do patrimônio natural e cultural, então estes são como matérias prima básica para a existência do fenômeno turístico (Figura 1).

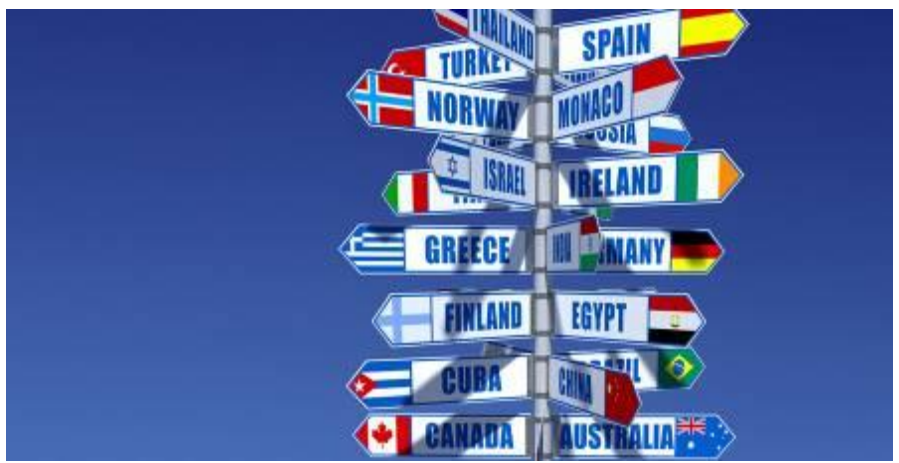

Figura 1: Turismo.

Figure 1: Tourism.

Fonte: http:portal.anhembi.br/cursosaperfeicoamento-em-gestao-de-turismo\#tab1 Source: http:portal.anhembi.br/cursosaperfeicoamento-em-gestao-de-turismo\#tab1

É um fenômeno social multicultural, complexo e diversificado, tanto que atualmente o turismo está apontado não só atrelado à ideia de atividade de lazer como o senso comum retrata, mas sim a diversidade de atrativos socioeconômicos que traz.

\section{Turismo de Base Local}

O Turismo é uma atividade socioeconômica, sendo sua expansão uma tendência contemporânea, que sempre esteve ligada ao modo de produção e ao desenvolvimento tecnológico, contribuindo com o fenômeno social, a inserção nas práticas cotidianas das pessoas, as iniciativas de reivindicação e exigências na melhoria da qualidade dos serviços. 
Nesse sentido, destacam-se as duas últimas décadas do século $X X$, cujas discussões foram marcadas em defesa e proteção do meio ambiente, na busca da mudança de paradigmas em nível global, onde gerou discussões permanentes na procura de alternativas de desenvolvimento sustentável, visando crescimento econômico compatível com a conservação da natureza (NOBRE, 2002, p.368).

Assim, "a procura pela natureza", expressão esta sugerida por KINKER (2002) faz uma reflexão do expressivo crescimento do turismo praticado em ambientes naturais, que segundo DIAS (2003, p. 33)

é uma indagação relevante, resultado de uma [...] procura por melhor qualidade de vida, [...] que alivia o estresse, e promove o surgimento de uma ética ambiental.

Nessa perspectiva surgiram várias segmentações de turismo, visando o contato direto do visitante com a natureza e a comunidade local. Dentre eles, destacam-se: o turismo de natureza, o turismo ecológico, o ecoturismo, o turismo sustentável e o mais recente, denominado de turismo de base comunitária ou turismo de base local. Vale destacar que, apesar de chegarem ao mesmo denominador comum como oferta da 'natureza e da comunidade local', tem objetivos e formas distintas.

Outro atributo essencial é o entendimento sistêmico da natureza, considerando permanentemente, a capacidade e limites nela existentes. Além da valorização e inserção da comunidade local nas estratégias de planejamento e de tomada de decisão, resultando na gestão participativa.

Em relação ao Turismo de Base Local ou Comunitária, Bartholo, Bursztyn e Sansolo (2009, p. 86) destacam que é uma nova modalidade do turismo, requerendo menor densidade de infraestrutura e serviços, visando a exploração dos recursos naturais e culturais locais, por meio da inclusão da comunidade no desenvolvimento e planejamento da atividade (Figura 2).

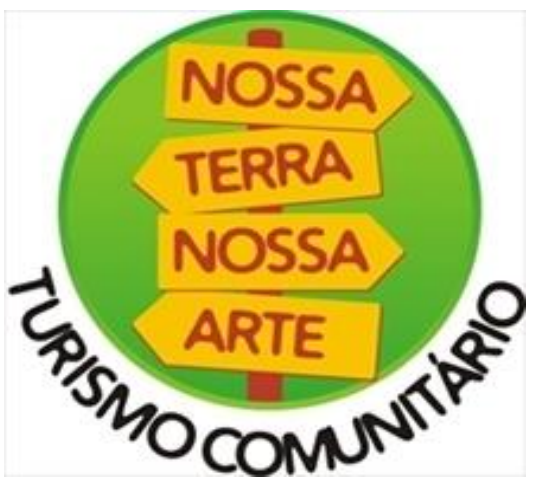

Figura 2: Turismo de Base Comunitária ou local.

Figure 2: Community Based Tourism or local.

Fonte: www.atitudessustentaveis.com.br/sustentabilidade/forca-turismo-base-comunitaria

Source: www.atitudessustentaveis.com.br/sustentabilidade/forca-turismo-base-comunitaria 
Para KINKER (2002, p. 74) o ecoturismo é o segmento indicado para esse tipo de atividade, na qual devem corresponder três aspectos básicos:

1) a conservação do ambiente visitado;

2) a conscientização ambiental tanto do visitante quanto do residente;

3) o desenvolvimento local/regional integrado.

Desse modo, o turismo de base local pode ser definido como uma alternativa da atividade do turismo que integra os modos e formas de vida dos comunitários residentes de determinada localidade, entrelaçando sua relação com a natureza, onde se tornam gestores, cuja ação transforma, cria e recria produtos, a partir de seu significado imaterial, observando os impactos sociais, econômicos, culturais e ambientais.

Analisa-se, portanto que, os desafios para colocá-los em prática, sobretudo diante da realidade brasileira e regional, tornam-se expressivamente difícil, indagando claramente que, não basta se apropriar do termo ecoturismo ou turismo de base local ou comunitária, deve ser difundido na origem de seus princípios. Nessa perspectiva, o Turismo de Base Local tem exercido forte influência sobre a utilização de patrimônios regionais salientando a cultura e a organização social dos povos tradicionais existentes no estado.

O turismo comunitário destaca-se pela mobilização da comunidade na luta por seus direitos contra grandes empreendedores da indústria do turismo de massa que pretendem ocupar seu território ameaçando a qualidade de vida e as tradições da população local. É preciso priorizar a satisfação de algumas necessidades humanas no que diz respeito à saúde, à educação, à moradia, ao lazer, ao emprego e à renda. Esses fatores implicam diretamente o processo de desenvolvimento do indivíduo, uma vez que o sujeito necessita de auto independência e habilidades para atuar em grupo, tornando-se protagonista de sua evolução e consequentemente de sua comunidade, já que a participação é considerada pelos estudiosos um processo de mobilização social e espaço de construção de cidadania, ou seja, primeiro ele deve ter seus direitos de cidadão contemplado para depois auxiliar 0 processo de desenvolvimento do local onde vive. (CARVALHO, 2007)

\section{Ecoturismo}

A definição abaixo é dada pelo Ministério do Meio Ambiente em conjunto com o EMBRATUR - Instituto Brasileiro de Turismo e segue aquela criada pela Sociedade Internacional de Ecoturismo (TIES ou The International Ecotourism Society), onde Ecoturismo ou turismo ecológico (Figura 3) é 
O segmento da atividade turística que utiliza, de forma sustentável, o patrimônio natural e cultural, incentiva sua conservação e busca a formação de uma consciência ambientalista por meio da interpretação do ambiente, promovendo o bem-estar das populações.

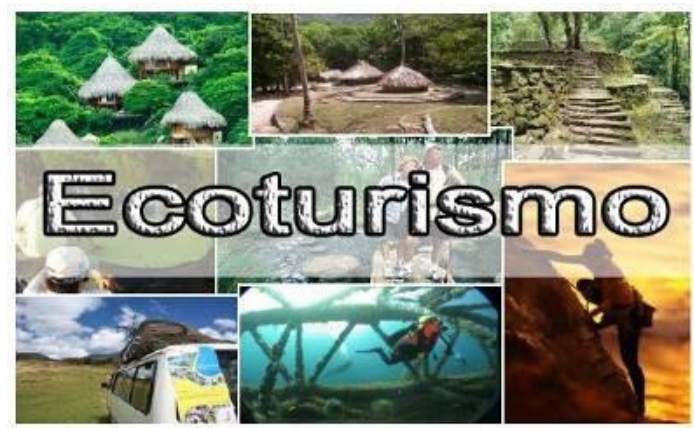

Figura 3: Ecoturismo.

Figure 3: Ecotourism.

Fonte: http://cidadebrasilturismo.blogspot.com.br/2014/06ecoturismo-esta-na-mira-dosturistas-da.html

Source: http://cidadebrasilturismo.blogspot.com.br/2014/06ecoturismo-esta-na-mira-dosturistas-da.html

Este segmento do turismo é caracterizado pelo contato com ambientes naturais, pela realização de atividades que promovam a vivência e o conhecimento da natureza e pela proteção das áreas onde ocorre. Isto é, ele está fundado nos conceitos de educação, conservação e sustentabilidade.

O ecoturismo pode ser entendido, então, como as atividades turísticas baseadas na relação sustentável com a natureza, comprometidas com a conservação e a educação ambiental.

É um segmento turístico importante ao fazer contribuições significativas para o bem-estar ambiental, social, cultural e econômico dos destinos e das comunidades locais, pois através dele são oferecidos incentivos econômicos eficazes para a conservação e valorização da diversidade biológica e cultural e, ajudando a proteger o patrimônio natural e cultural do lugar a ser impactado pela atividade turística.

O ecoturismo se promove como uma ferramenta para capacitar as comunidades locais a alcançar um desenvolvimento sustentável. Além disso, o ecoturismo tem incentivado a aplicação de práticas sustentáveis aos demais segmentos da indústria do turismo, minimizando transformações e procurando manter as tradições do lugar e dos seus autóctones.

Ecoturismo é o deslocamento responsável a áreas naturais, visando a preservação do meio ambiente e promover o bem estar da população local (Diretrizes para uma política nacional de Ecoturismo, MICT/MMA, 1995).

Segundo o Ministério do Turismo (2010), o Ecoturismo surgiu influenciado pelas transformações do século $X X$ levando uma maior interação entre o homem e o meio natural. Este conceito é adotado para 
focalizar a natureza como meio de educação que contribui para uma maior preservação e conservação das áreas atuadas.

O Ecoturismo traz efeitos benéficos e conservação aos meios visitados aliados a uma educação ambiental para os visitantes, onde serão capazes de se conscientizarem da necessidade e importância da preservação ambiental (NEIMAN, 2002, p. 78).

De acordo com Ribeiro e Barros (2001, p. 08), esta prática possibilita a interação homem-natureza como forma de preservação, sustentabilidade, conscientização ambiental, ou seja, é um meio de relacionar ações políticoambientais com propostas de valorização dos recursos naturais do país.

Segundo o Grupo de Trabalho Interministerial em Ecoturismo, diz que:

Ecoturismo é um segmento da atividade turística que utiliza, de forma sustentável, o patrimônio natural e cultural, incentiva sua conservação e busca a formação de uma consciência ambientalista através da interpretação do ambiente, promovendo o bem- estar das populações envolvidas (MICT, 2010).

Neste contexto, o Ecoturismo é uma estratégia de incentivar a preservação ambiental, em outras palavras, envolve tanto um sério compromisso com a natureza como uma grande responsabilidade social.

\section{O Ecoturismo de base comunitária}

O crescimento da atividade turística, assim como de outras atividades econômicas, requer planejamento e ordenamento para minimizar os impactos negativos e, principalmente, potencializar os positivos. Entretanto, em diversas regiões do país, observamos que a expansão desordenada resultou na sobreposição dos impactos negativos, inclusive com prejuízo no médio prazo para a preservação da imagem do ambiente (CORIOLANO, 2009, p. 396).

A prioridade para a dimensão estritamente mercadológica, em detrimento dos princípios da sustentabilidade social, cultural, ambiental, provoca a desestruturação da cultura local, eleva os índices de vazamentos de renda, descaracteriza ambientes naturais, estimula a especulação imobiliária e exclusão territorial de residentes. Esses impactos são ainda mais deletérios nas localidades mais pobres onde a expansão do turismo é apresentada como alternativa de melhoria das condições sociais, mas se transforma em fator de agravamento da situação social (COSTA NOVO, 2014, p. 45-56).

Para se entender aos impactos negativos do turismo e aproveitar os benefícios da atividade, observamos que em algumas localidades, de diferentes países, por meio da mobilização e organização da sociedade civil, surgiram diversas iniciativas diferenciadas, baseadas nos modos de vida locais. Nesta perspectiva, estruturaram-se as práticas de turismo de base 
comunitária (Figura 4), também conhecidas como "turismo comunitário" (BURSZTYN; BARTHOLO, 2012, p. 97-116).

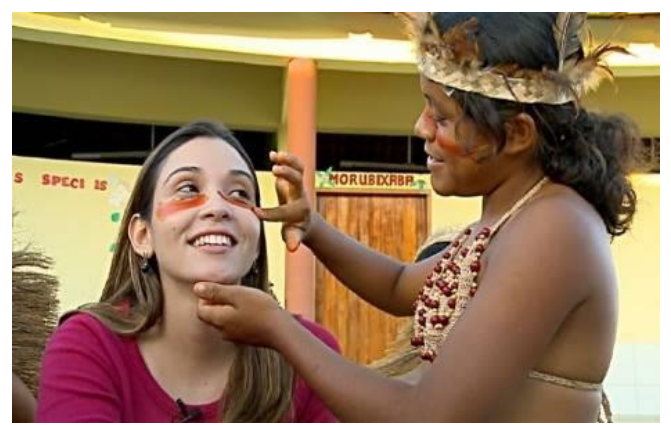

Figura 4: Turista recebendo pintura indígena tradicional

Figure 4: Tourist getting traditional Indian painting

Fonte: http://ecoturismoufsm.blogspot.com.br/2012/10turismo-de-base-comunitaria.html

Source: http://ecoturismoufsm.blogspot.com.br/2012/10turismo-de-base-comunitaria.html

\section{Sustentabilidade}

O termo Sustentabilidade é usado para definir ações e atividades humanas que visam suprir as necessidades atuais dos seres humanos, sem comprometer o futuro das próximas gerações. Ou seja, a sustentabilidade está diretamente relacionada ao desenvolvimento econômico e material sem agredir o meio ambiente, usando os recursos naturais de forma inteligente para que eles se mantenham no futuro, assim a humanidade pode garantir 0 desenvolvimento sustentável para as futuras gerações garantindo uma melhor qualidade de vida.

$\mathrm{Na}$ prática está definida como a capacidade que o indivíduo ou um grupo de pessoas tem em se manterem dentro de um ambiente sem causar impactos marcantes a esse ambiente.

Mas, apesar da sustentabilidade estar associada diretamente ao meio ambiente e a tudo o que envolve este, não está limitado somente a está área. A sustentabilidade está relacionada a outros setores da sociedade como a economia, a educação e a cultura, sem que estes agridam o meio ambiente (Figura 5).

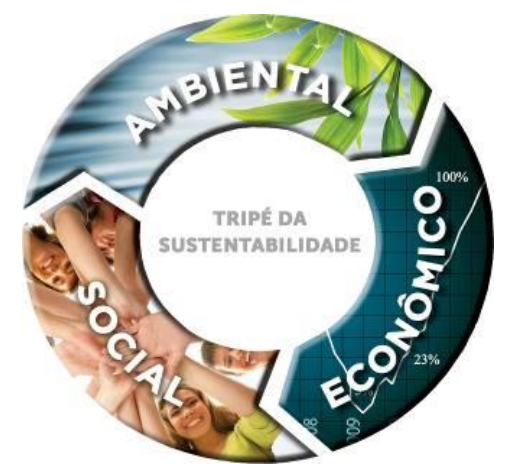

Figura 5: Tripé da Sustentabilidade.

Figure 5: Sustainability Tripod.

Fonte (Source): $\underline{\text { htpp://www.delboniauriemo.com.br/paginasinstitucionalsustentabilidade- }}$ delboni 
Um conceito amplo está associado a soluções, caminhos e planos que busquem resgatar adoções de práticas sustentáveis na vida de cada pessoa e atinjam uma melhora comum a todos. Contribuir com novas vivências e experiências pessoais e repassar estas ao coletivo é um fator decisivo para possibilitar a prática da sustentabilidade.

No mundo atual, é visível a preocupação cada vez maior com os resíduos e efluentes descartados, com a poluição, com a perda da biodiversidade, com fenômenos como o aquecimento global causado, sobretudo, pela queima de combustíveis fósseis e com outras agressões causadas pelo homem à natureza, como resultado de suas atividades (SACHS, 2004, p. 36).

Devido a tais preocupações, foram obtidas, nos últimos anos, importantes conquistas ambientais, com participação de movimentos ecológicos e demais interessados na preservação do nosso patrimônio natural. Empresários de vários setores, inclusive do turismo, começaram a adotar posturas ambientais corretas. Neste sentido, o ecoturismo começou a disparar, pois utiliza de forma sustentável o patrimônio natural e cultural, incentiva sua conservação e busca a formação de uma consciência ambientalista através da interpretação do ambiente, promovendo o bemestar das populações envolvidas (SMA/UFRJ, 2010).

O setor de turismo é um dos que mais tem crescido nos últimos anos. Está ligado diretamente ao meio ambiente, sendo capaz de expor nosso patrimônio natural e cultural, onde a natureza é o produto a ser vendido. Se não for planejado corretamente, acaba-se transformando num fator de poluição e destruição.

Segundo Irving (2005, p. 01-07), o ecoturismo é o segmento do turismo que possibilita valorizar e preservar o patrimônio, viabilizando retornos econômicos, proporcionando uma educação ambiental, através da conscientização da importância da preservação do meio ambiente, gerando benefícios para comunidade. Possibilita a eficácia e eficiência na atividade econômica, mantendo a diversidade e estabilidade do meio ambiente, atuando como instrumento de orientação, sensibilização e equilíbrio entre os desgastes causados pelo desenvolvimento econômico e a necessidade de preservar o meio ambiente.

\section{Empreendedorismo}

Empreendedorismo é o estudo voltado para o desenvolvimento de competências e habilidades relacionadas à criação de um projeto (técnico, científico, empresarial). Tem origem no termo empreender que significa realizar, fazer ou executar. O empreendedor é aquele que apresenta determinadas habilidades e competência para criar, abrir e gerir um negócio, gerando resultados positivos.

A definição original de empreendedor, do grego, condutor, mostrando que o empreendedorismo tem mais chances de sucesso através do empresarismo, quer dizer, 
não basta o gosto por assumir riscos, é importante um comportamento de empresário, que organiza, planeja e estuda profundamente o assunto para ter uma atividade com sucesso consistente. Por isso ele distingue empreendedorismo de empresarismo, e afirma que a mistura é mais saudável e promissora (MOSSO, 2010, p. 491).

Uma vez identificado o potencial turístico de uma determinada comunidade e caracterizados os elementos que compõem o patrimônio cultural selecionado, os órgãos governamentais deverão adotar mecanismos de incentivo não só para programar a atividade do ecoturismo pretendida, como também para fornecer ou providenciar a infraestrutura, a fiscalização e o monitoramento necessário.

\section{Conclusões}

É fato observar que a atividade do ecoturismo possui seus pontos positivos e negativos, sendo em função dessa perspectiva que a análise e a prática do segmento ecoturismo faz-se importante.

Portanto, a pesquisa bibliográfica possibilitou um amplo alcance de informações, além de permitir a utilização de dados dispersos em inúmeras publicações, auxiliando também na construção, ou na melhor definição do quadro conceitual que envolve o objeto de estudo proposto.

Em todo o desenvolvimento da metodologia, o objetivo foi configurar o Ecoturismo como estratégia econômica voltada para as comunidades de base, onde a mediação do conhecimento precisa ir além da simples transmissão, onde os atores sociais poderão contribuir para que seja feita de forma sustentável.

Ecoturismo é um segmento da atividade turística que utiliza, de forma sustentável, o patrimônio natural e cultural, incentiva sua conservação e busca a formação de uma consciência ambientalista através da interpretação do ambiente, promovendo 0 bem-estar das populações envolvidas e dos atores sociais. $O$ aproveitamento desse potencial por meio do desenvolvimento de estratégias que fortaleçam o turismo participativo, solidário e sustentável é, sem dúvida, uma grande oportunidade para o país.

Conforme estabelecido na introdução do trabalho, a teoria apresentada não tem a pretensão de esgotar o assunto, nem ser considerada uma verdade indiscutível. Na verdade, ela apresenta alguns pontos comuns que precisam ser considerados, no processo da avaliação da viabilidade da inserção do Ecoturismo numa determinada localidade e na vida de seus autóctones.

Cada ponto apresentado poderia ser discutido ampla e exaustivamente, o que, aliás, postulam as ideias e ideais do Turismo e do seu segmento Ecoturismo que busca o cognitivo, o lúdico e a interação com todos envolvidos. 
As lacunas existentes são provenientes de ser um assunto novo e pouco explorado, em constante aprimoramento e pesquisas, o "mundo" e a "indústria" do Turismo e do segmento Ecoturismo é infinito e, cada lugar terá uma novidade, algo novo a ser apreciado e a ser explorado com inúmeras visões e com experiências inesquecíveis e marcantes para todos os envolvidos.

O campo do Turismo é muito abrangente e ainda tem muitas oportunidades a serem apreciadas, vividas e exploradas de forma participativa e sustentável, o Brasil é solidário, é participativo e é único.

\section{Referências bibliográficas}

ANGELO, E.R.B. Métodos e Técnicas de Pesquisa em Turismo. Rio de Janeiro: Fundação CECIERJ, 2012.

ASSOCIAÇÃO BRASILEIRA DE NORMAS TÉCNICAS. NBR6029: apresentação de livros. Rio de Janeiro, 1993. NBR 6028(NB88) da ABNT.

ASSOCIAÇÃO BRASILEIRA DE NORMAS TÉCNICAS. NBR6023: normas para referências bibliográficas. Rio de Janeiro, 2002.

BARTHOLO, R.; SANSOLO, D.G.; BURSZTYN, I. (org.). Turismo de base comunitária: diversidade de olhares e experiências brasileiras. Rio de Janeiro: Letra e Imagem, 2009.

BENI, M.C. Análise Estrutural do Turismo. 2. Ed. São Paulo: SENAC, 2001.

BRASIL. MINISTÉRIO DO TURISMO. Ecoturismo: orientações básicas. 2. ed. - Brasília: Ministério do Turismo, 2010.

BURSZTYN, I. E BARTHOLO, R. 2012. O processo de comercialização do turismo de base comunitária no Brasil: desafios, potencialidades e perspectivas. Sustentabilidade em Debate, Rio de Janeiro, 2009, 3(1): 97116.

CARVALHO, V. O turismo comunitário como instrumento de desenvolvimento sustentável. Disponível em: https://pt.wikipedia.org/wiki/Turismo comunit\%C3\%A1rio. Acesso em: 17 Ago 16.

CORIOLANO, L.N.M.T. O Turismo Comunitário no Nordeste Brasileiro. In: BARTHOLO, R; SANSOLO, D.G.; BURSZTYN, I. (Orgs). Turismo de Base Comunitária: Diversidade de Olhares e Experiências Brasileiras. Rio de Janeiro: Letra e Imagem, 2009.

COSTA NOVO, C.B M.; CRUZ, J.G. Turismo Comunitário: Reflexões no Contexto Amazônico. Manaus: Edua, 2014, p. 184.

DIAS, R. Turismo sustentável e meio ambiente. São Paulo: Atlas, 2003.

IRVING, M.A. Revisando significados em Sustentabilidade no planejamento turístico. Caderno Virtual de Turismo, Instituto Virtual de Turismo, Rio de Janeiro, n.18, dez. 2005. P.1-7. 
KINKER, S. Ecoturismo e conservação da natureza em parques nacionais. Campinas, SP: Papirus, 2002, p. 224.

LAKATOS, E.M.; MARCONI, M. A. Técnicas de pesquisa. 6. ed. São Paulo: Atlas. 2006. p. 289.

MINISTÉRIO DA INDÚSTRIA, COMÉRCIO E TURISMO - MICT, MINISTERIO DO MEIO AMBIENTE - MMA. 1994. Diretrizes para uma política Nacional de Ecoturismo. Brasília, DF.

MINISTÉRIO DO MEIO AMBIENTE. 1999. Conduta Consciente em Ambientes Naturais. Folheto. Brasília, DF.

MOSSO, M.M. Pequena Empresa e Empreendedorismo: Eternamente Fênix. Rio de Janeiro, Qualitymark, 2010.

NEIMAN, Z. (org.). Meio Ambiente, Educação e Ecoturismo. Barueri, SP: Manole, 2002, p. 101.

NOBRE, M.; AMAZONAS, M.C. (Org.). Desenvolvimento Sustentável: A institucionalização de um conceito. 2 ed. Brasília: Ed. IBAMA, 2002, P. 368.

PANOSSO NETTO, A. Filosofia do Turismo. São Paulo: Aleph, 2011.

REJOWSKI, M.; COSTA, B.K. (Orgs.).. Turismo contemporâneo: desenvolvimento, estratégia e gestão. São Paulo: Atlas, 2003.

RIBEIRO, G.L.; BARROS, F.B. A Corrida Por Paisagens Autênticas: Turismo, Meio Ambiente e Subjetividade na Contemporaneidade. Série Antropologia 171. Brasília 2001. Disponível em: $<$ http://www.unb.br/ics/dan/Serie171empdf.pdf> Acesso em: 10 Jul 16.

SACHS, I. Desenvolvimento e Meio Ambiente: Includente, sustentável, sustentado. Rio de Janeiro: Garamond, 2004.

SALVATI, S.S. Planejamento do Ecoturismo. In: MITRAUD, S (org). Manual de Ecoturismo de Base Comunitária: Ferramentas para um planejamento responsável. Brasília: WWF, 2003, p. 33-38.

SÃO PAULO (Estado). SECRETARIA DO MEIO AMBIENTE. Ecoturismo Cadernos de Educação Ambiental, 5. Autores: Oliveira, A. C. L.; Matheus, F. S.; Santos, R. P.; Bressan, T. V.. São Paulo: SMA, 2010.

UNIVERSIDADE FEDERAL DO RIO DE JANEIRO - UFRJ. Relatório técnico-científico: Marco referencial teórico para o Turismo de Base Comunitária. Rio de Janeiro, 2011.

WWF - Brasil. Manual de Ecoturismo de Base Comunitária: Ferramentas para um planejamento responsável. Brasília: WWF, 2006, p. 20. 


\section{Nota:}

1 Professor e Bolsista de Incentivo ao Pesquisador (BIP) da Pró-reitoria de Pesquisa e Pós-graduação da Universidade Estadual de Goiás (UEG).

Eduardo Spaolonse: Colégio Militar de Manaus, Manaus, AM, Brasil.

E-Mail: spaolonsecurso@gmail.com

Link para o currículo Lattes: http://lattes.cnpq.br/9507085704687420

Suzana da Silva de Oliveira Martins: Centro de Biotecnologia da Amazônia, Farmacologia, Toxicologia e Biotério, Manaus, AM, Brasil.

E-Mail: svcjean@yahoo.com.br

Link para o currículo Lattes: http://lattes.cnpq.br/8483413799152587

Data de submissão: 26 de agosto de 2016

Data de recebimento de correções: 27 de novembro de 2016

Data do aceite: 27 de novembro de 2016

Avaliado anonimamente 